\title{
Litteratur
}

Cassels Johnson, David, 2013: Language Policy. Research and Practice in Applied Linguistics. London: Palgrave Macmillan.

Cooper, Robert L., 1989: Language Planning and Social Change. Cambridge: Cambridge University Press.

Widmark, Gun, 2007: När Språknämnden var ung. I: Birgitta Lindgren (red.): Nämnd, inte glömd. Historik över Nämnden för svensk språkvård och Svenska språknämnden 1944-2007. (Skrifter utgivna av Svenska språknämnden 95.) Stockholm: Svenska språknämnden. S. 60-64.

Olle Josephson

Norrthon, Stefan, 2020: Teaterrepetitionens interaktion. Professionella praktiker i ett repetitionsarbete från manus till föreställning. (Stockholm Studies in Scandinavian Philology, New Series 68.) 157 s. Stockholm: Stockholms universitet. ISSN 0562-1097, ISBN 978-91-7911-048-2.

Stefan Norrthons avhandling uppehåller sig vid en aktivitet som ännu är i princip outforskad i egenskap av tidsbunden kreativ process: teaterrepetitionen. Utifrån ett samtalsanalytiskt och interaktionsanalytiskt perspektiv identifierar Norrthon ett antal centrala praktiker i professionellt teaterarbete. Norrthon passar också på att göra upp med myten om regissören som någon som kommunicerar sina konstnärliga intentioner via skådespelarna. I stället beskrivs repetitionsprocessen och de beslut som där fattas som ett tätt och kreativt samarbete mellan främst skådespelare och regissör.

Avhandlingen, som är av sammanläggningstyp, består av en kappa om 70 sidor, efter vilken resten av volymen utgörs av tre fristående artiklar. Vid tidpunkten för tryckningen var artikel 1 publicerad i Journal of Pragmatics, artikel 2 antagen för publicering i Journal of Applied Linguistics \& Professional Practice medan artikel 3 fortfarande var under granskning.

I kappans inledande kapitel anger Norrthon två syften med sitt avhandlingsprojekt, ett empiriskt och ett teoretiskt och metodologiskt. Medan det förra formuleras som »att undersöka en professionell repetitionsprocess som situerad interaktion och som longitudinell process, med fokus på skådespelarnas och regissörens arbete» (s. 3), anges det senare till »att bidra till utvecklingen av terminologi och metoder att använda i longitudinell interaktionsanalys [...] avhandlingen [har] också ambitionen att lämna något bidrag till teaterns utövare eller teoretiker» (s. 4).

Det är alltså till samtalsanalysen och den interaktionellt inriktade språkforskningen som detta arbete vill utgöra ett bidrag. Mer precist intar Norrthon ett multimodalt perspektiv på interaktion, där kommunikation och handlande med hjälp av olika kroppsbaserade och materiella resurser (tal, blickar, gester, kroppshållning, rörelse, artefakter m.m.) i sitt rumsliga och tidsmässiga sammanhang står i fokus. Ett centralt tema i avhandlingen är även hur en teaterföreställning växer fram över tid, och därmed an- 
knyts till longitudinell interaktionanalys, vilket är ett tämligen nytt område inom fältet.

Med en imponerande videodokumentation av Riksteaterns arbete - från de allra första manusgenomgångarna till premiären - med att sätta upp Lucy Prebbles Effekten (2013) som empirisk bas tar Norrthon itu med följande övergripande frågeställningar:

1) Vilka interaktionella, professionella praktiker engagerar sig deltagarna i under arbetsprocessen, och på vilket sätt (ett interaktionsperspektiv)?

2) Hur kombineras manuset med andra multimodala resurser i utvecklingen från skriven text till föreställning (ett föreställningsperspektiv)?

Kappans andra kapitel behandlar tidigare forskning om teater och teaterarbete. Norrthon försöker inte leverera någon heltäckande litteraturöversikt utan begränsar framställningen till relevant forskning utifrån syftet och frågeställningarna. Norrthon visar i sin genomgång att språkvetenskapen och teatersemiotiken med få undantag studerat teater som produkt snarare än process. För språkvetenskapen gäller dessutom att det främst varit manuset som studerats, inte den spelade föreställningen. Om repetitionsarbetet från manus till föreställning ibland varit föremål för teoretisering, så har denna knappast varit empiriskt grundad. Detta kan delvis förklaras med att det är svårt för forskaren att få tillgång till repetitioner. Ibland har dock repetitioner även framställts som direkt olämpliga att studera, då de antagits sakna struktur.

Norrthon finner tidigare forskning om repetitioner av flera slag: teaterarbetare som berättar om sina egna erfarenheter, etnografiska studier och interaktionellt inriktad språkvetenskap. Fokus har bland annat legat på de olika rollerna i repetitionsprocessen, och vilken betydelse de olika deltagarna har för uppsättningens slutliga form. På senare tid har man inom interaktionsforskningen börjat identifiera professionella och aktivitetskonstituerande praktiker i teaterarbete. Slutligen kan nämnas att Norrthon endast lyckats identifiera tre studier som i likhet med den aktuella avhandlingen anlagt ett multimodalt perspektiv.

I det tredje kapitlet presenterar Norrthon det anlagda teoretiska perspektivet och den analysmetod som använts. Då Norrthon grundar sitt arbete i den multimodala interaktionsanalysen, som har tydliga band till etnometodologisk samtalsanalys (conversation analysis), ligger fokus på mänskligt handlande, och hur handlingar utförs på igenkännbara sätt med diverse kommunikativa resurser, språkliga såväl som kroppsliga, i multimodala Gestalts. Norrthon går igenom såväl central terminologi som definierande aspekter $i$ analysmetoden, särskilt påvisande av responsevidens som ett sätt att prioritera »deltagarperspektivet». Efter en diskussion om metodens relevans för att studera teaterrepetitioner som ett slags institutionell aktivitet introduceras den longitudinella samtalsanalysen. Här jämför forskaren samma typ av handling vid olika tidpunkter i syfte att kartlägga utveckling i exempelvis lärprocesser, något som dock kan ses som problematiskt i förhållande till deltagarperspektivet. Vidare diskuteras tre nyckelbegrepp i avhandlingen: »aktivitet», här själva repetitionen, »professionell praktik», definierat som »olika delprocedurer som repetitionen består av [...] något deltagare praktiskt gör, som är kopplat till traditioner» (s. 23), och de »sociala handlingar» med vilka deltagare engagerar sig i praktiker och aktiviteter.

Kapitlets sista rubrik är uppfriskande: »Tre huvudpoänger med att undersöka denna 
aktivitet med denna metod». Dessa poänger uppges vara att repetitionen är underutfors$\mathrm{kad}$, att teoretiskt intressanta beröringspunkter mellan interaktionsanalys och teaterarbete föreligger, och slutligen att det även kan hjälpa till att avmystifiera teatern, genom att i detalj beskriva dess kreativa processer.

Närmare uppgifter om datamaterial och insamlingsmetod får läsaren $i$ kappans fjärde kapitel. Som redan nämnts utgörs data till studien av videoinspelningar av Riksteaterns repetitionsarbete med Lucy Prebbles pjäs Effekten. Norrthon följde under 2015 Riksteaterns 45 dagar långa repetitionsarbete fram till den svenska premiären. Repetitionsarbetet dokumenterades med tre kameror, och totalt genererades ca 85 timmar videoinspelningar. I detta kapitel ges även en beskrivning av inspelningsarbetet, olika etiska överväganden gällande exempelvis datainsamling och datahantering, liksom en diskussion av betydelsen av Norrthons tidigare skådespelarutbildning för hans möjligheter att få tillträde till denna typ av aktivitet och att också förstå den. Kapitel fyra avslutas med en diskussion om hur det inspelade materialet behandlats i analysarbetet, såväl vad gäller val av exempel som val av fenomen att återge i de multimodala transkriptionerna.

Kapitel fem innehåller sammanfattande diskussioner av de tre ingående delstudierna.

Delstudie 1 har titeln »To Stage an Overlap - The longitudinal, collaborative and embodied process of staging eight lines in a professional theatre rehearsal process». Denna delstudie handlar om hur skådespelarna och regissören under repetitionsperioden gradvis mejslar fram ett åtta repliker långt segment i manuset till dess slutliga form. Syftet anges till »att kartlägga hur skådespelarna använder både auditiva och visuella resurser när de läser, eller spelar (under repetitioner eller inför publik) de åtta replikerna under processen och att identifiera utvecklingsbanor för hur de använder dessa resurser över tid» (s. 38-39).

Denna delstudie genererar flera intressanta resultat. Ett första är att gestaltningen av den överlappning mellan två repliker som anges i manus ändras över tid på ett »icke-linjärt» sätt, allteftersom skådespelarna lär sig sina repliker och resonerar om hur ett gräl egentligen går till. Vidare belyser delstudien hur manuset som fysiskt objekt påverkar sättet som skådespelarna kan gestalta skeendet på under repetitionerna. Norrthon visar här också att den kroppsliga gestaltningen inleds redan första dagen och att skådespelarna uppvisar en mycket finstämd känslighet inför vad den andra gör under repetitionsarbetet. Diskussionen av delstudie 1 avslutas med en presentation av de professionella praktiker som identifierats: sceneriläggning, förkroppsligad läsning, snabbkontroll av den andre, inventera verkligheten samt inventera möjliga multimodala resurser. Dylika praktiker utgör alltså konstituerande aspekter av teaterrepetitionen som aktivitet.

Delstudie två har givits titeln »Framing in theater rehearsals - A longitudinal study following one line from page to stage». Denna studie syftar till »att synliggöra hur deltagarna utvecklar föreställningen avseende en enskild replik genom att utveckla olika inramningar» (s. 42). Med fokus på en replik som utgör en viktig vändpunkt i pjäsen visar denna delstudie först och främst att olika slags kontextuella inramningar som inte finns angivna i manuset utvecklas av deltagarna i deras arbete med att sätta upp pjäsen. Ett slags progression identifieras också, från att tidigt i repetitionsprocessen i samtal etablera sociala och psykologiska kontexter, till att, utifrån den etablerade gemensamma synen om vilka dessa ska vara, röra sig mot ett mera fysiskt gestaltande. I likhet med delstudie 1 finner Norrthon även här en icke-linjär utveckling vad gäller gestaltandet, 
något som grovt kan beskrivas som »stilla spel» initialt, via mera »rörligt spel» en bit in $i$ arbetet till en återgång till ett mera »stilla spel» vid premiären. De professionella praktiker som identifierats i denna delstudie benämns »återanvändning (av kontexter och inramningar)» och »etikettering (av inramningar)».

»The timing of transitions in theatre rehearsals» är titeln på avhandlingens tredje delstudie. Här fokuseras hur skådespelare och regissör mot slutet av repetitionsperioden gemensamt åstadkommer tajming $\mathrm{i}$ övergångar mellan scener. Ett viktigt redskap i detta arbete är s.k. stick (eng. cues), eller beteenden som övergångar kan hängas upp på. Frågeställningarna rör vilka multimodala resurser som deltagarna använder sig av för att utveckla stick och hur de gör det samt vem som engagerar sig på vilket sätt i arbetet att hitta lösningar för övergångar mellan scener. Ett första resultat är att det snarare är kroppen än repliker som används vid utvecklande av stick, vilket Norrthon kopplar till att ett krav på stick är att de bör vara såväl konkreta som avgränsade i tiden. Ett andra resultat belyser hur stick utvecklas i samspel och här identifieras en särskilt sekvenstyp, »stickkandidat - precisering - bekräftelse», vilken är återkommande i materialet. Vidare står det klart, menar Norrthon, att medan regissören förvisso har ansvar för övergripande tajming i tillgängliga data, är det de direkt inblandade skådespelarna som arbetar fram praktiska lösningar på en mera finkornig nivå under repetitionens gång. Norrthon finner vidare att övergångar med stick är interaktionella processer, där en skådespelares beteende antas kunna styra publikens fokus under en övergång mellan scener, exempelvis för att ge andra tid att göra det de behöver göra. De professionella praktiker som identifierats i denna delstudie är att »utveckla stick» och »styra fokus».

I kappans sjätte kapitel, vilket avslutar den svenskspråkiga framställningen, diskuteras frågeställningarna och resultaten av de tre delstudierna. Den första övergripande frågeställningen rör aktivitetsspecifika professionella praktiker, vilka visar sig stå i ett reflexivt förhållande till processen. Just det att deltagarna bygger en gemensam grund och lär sig manus under repetitionsprocessen är något som påverkar språket och användningen av övriga multimodala resurser. Detta resulterar i en icke-linjär process från framförallt verbal manusläsning via ett slags expressiv kulmen där gestaltningen provas ut för att sedan landa i något mera sparsmakat. Det står därmed också klart att en teaterföreställning är ett verk med många upphovspersoner: skådespelarna och regissören lägger till innehåll när de förkroppsligar manuset, utvecklar kontexter för helheten och skapar tajming i övergångar. Norrthon identifierar kroppen som det centrala instrumentet för att utveckla en föreställning, och deltagarnas gestaltande arbete består av att undersöka möjliga kombinationer av multimodala resurser.

Angående den andra övergripande frågan, om utvecklingen från skriven text till föreställning, visar avhandlingen att repetitionsarbete är en systematisk aktivitet, väl värd att studera. Avhandlingen visar också viktiga aspekter av hur det går till, och därmed avmystifieras repetitionsarbetet. Som redan nämnts ovan har det ibland setts som olämpligt att studera repetitioner då de betraktats som ostrukturerade. Norrthon skriver skarpt: »Repetitionen är inte slumpartad, men en produktinriktad jämförelse mellan manus och föreställning riskerar att bli det, eftersom den missar processen i vilken specifika deltagare i ett specifikt sammanhang, moment för moment och över tid förhandlar om, och utvecklar det som ska bli föreställningen» (s. 52). När deltagarna gestaltar ett manus gör de även berättelsen till (delvis) sin egen. Kappan avslutas därefter med en engelsk sammanfattning och en tiosidig referenslista. 
Stefan Norrthons avhandling visar att han väl behärskar den multimodala interaktionsanalysens teori och metoder, och är kapabel att leverera klart originella resultat av relevans såväl för fältet som för den vidare teaterforskningen. Särskilt imponerande är den datainsamling som ligger till grund för arbetet, inte endast att Norrthon fått tillgång till fältet utan också hur repetitionsarbetet videodokumenterats och därefter transkriberats med stor noggrannhet. Vissa smärre skavanker i transkriptioner och översättningar till engelska bör inte skymma den överlag goda helheten vad gäller datahanteringen. Ibland anar man i analysen en lust att skriva fram alltför tydliga resultat, det blir lite för svart-vitt. Det antagligen tydligaste exemplet på detta är när Norrthon kommer fram till att teaterarbete snarare är ett samarbete mellan skådespelare och regissör än (enkelriktad) instruktion från regissören. Redan många av denna avhandlings egna utdrag visar dock ofta regissören i färd med att leverera just instruktioner till skådespelarna - det måste alltså vara både och. Ytterligare invändningar kan göras mot att den för interaktionsanalysen centrala sekvensanalysen särskilt i kappan får stå tillbaka väl mycket till förmån för den jämförande longitudinella analysen, och att man på något ställe kan skönja en lust att generalisera bortom vad som är rimligt med hänsyn till tillgängliga data.

Stefan Norrthon skriver bra, och har då och då också modet att uttrycka sig friskt okonventionellt. Ett råd till framtida läsare är att börja med artiklarna och sedan läsa kappan. Börjar man med kappan får man vänta väl länge på det första transkriberade datautdraget (vilket återfinns först på s. 46). Dessutom hjälper analyserna i artiklarna läsaren att förstå många potentiella oklarheter i kappan.

Kappan är relativt kort, och möjligtvis upprepas väl mycket innehåll från artiklarna i stället för att utnyttja utrymmet för att ge läsaren något annat och mera. Å andra sidan är det bra att kappan erbjuder en uppsättning begrepp som håller ihop avhandlingen på ett tydligt sätt. Sammanfattningsvis måste sägas att Stefan Norrthon genom sin avhandling givit oss mycket ny kunskap om teaterrepetitionen som institutionell aktivitet och dess konstituerande praktiker.

\section{Mathias Broth}

Sandberg, Malin, 2020: Från beslut till broschyr. Intertextualitet, äldre och kultur i texter inom en statlig satsning. (Göteborsstudier i nordisk språkvetenskap 40.) Diss. 209 s. Göteborg: Göteborgs universitet. ISSN 1652-3105, ISBN 978-91-87850-77-6.

Malin Sandberg undersöker i sin avhandling texter inom en statlig kultursatsning för äldre. Närmare bestämt handlar det om textkedjor från regeringens beslut via Kulturrådets utlysning, till ansökningar, rapporter om kulturprojekt och slutligen Kulturrådets broschyrer om projekten - kort sagt om vägen från beslut till broschyr.

Avhandlingen består av nio kapitel. I det första kapitlet presenteras och motiveras undersökningen. Sandbergs syfte är att »dels kartlägga hur intertextuella relationer tar sig uttryck i texter från en statlig satsning på kultur för äldre, dels belysa hur diskurser om 